\title{
Efficacy and safety outcomes of fractional flow reserve in guiding clinical therapy of non-ST- segment elevation myocardial infarction compared with angiography alone in elderly Chinese patients
}

\author{
This article was published in the following Dove Press journal: \\ Clinical Interventions in Aging \\ 28 November 2016 \\ Number of times this article has been viewed
}

\section{Zhao Zhang* \\ Ke Li* \\ Jinwen Tian}

Department of Cardiology, Chinese People's Liberation Army General Hospital and Hainan Branch, Sanya, People's Republic of China

*These authors contributed equally to this work
Correspondence: Jinwen Tian Department of Cardiology, Chinese People's Liberation Army General Hospital and Hainan Branch, Jianglin Street, Haitang Bay, Sanya 572013, People's Republic of China

Tel +86 I56 92538940

Email tjwsqr.2000@163.com
Objective: Fractional flow reserve (FFR) is an innovative method for evaluating the physiological significance of a coronary stenosis, but its validity is less certain in patients with non-ST-segment elevation myocardial infarction (NSTEMI). It is important to assess whether FFR is effective and safe in patients, especially elderly Chinese patients, with NSTEMI. As the first one in China, the purpose of this study was to establish the efficacy and safety outcomes of FFR in guiding clinical therapy of NSTEMI compared with angiography alone in elderly Chinese patients.

Patients and methods: This prospective randomized controlled study included 220 patients with NSTEMI older than 65 years. Patients were assigned in a ratio of 1:1 to the FFR-guided group and the angiography-guided group, and their outcomes were evaluated after 1 year of follow-up.

Results: The mean age of the patients was $70 \pm 3.6$ years, and $69.6 \%$ were men. Baseline characteristics of the patients had no differences between the two groups ( $P>0.05$ for all). No differences in adverse events, including major adverse cardiovascular event, major adverse cardiovascular and cerebrovascular event, cardiovascular death, nonfatal myocardial infarction, heart failure, stroke, transient ischemic attack, all-cause mortality, contrast nephropathy, and major bleeding, was observed between the two groups during the follow-up ( $P>0.05$ for all). The number of patients receiving medical therapy alone in the FFR-guided group was significantly more than that in the angiography-guided group $(P<0.05)$.

Conclusion: Compared with angiography-guided standard therapy, FFR reduced the application of percutaneous coronary intervention and obtained similar outcomes, demonstrating that FFR was effective and safe in guiding clinical therapy of NSTEMI in elderly Chinese patients.

Keywords: elderly Chinese patients, fractional flow reserve, non-ST-segment elevation myocardial infarction

\section{Introduction}

Coronary artery disease (CAD) is a leading cause of morbidity and mortality worldwide. ${ }^{1,2}$ Angiography is the current standard method applied for clinical therapy of CAD. However, visual assessment of the anatomical severity of a coronary stenosis is subjective and correlates poorly with physiological significance, potentially resulting in inappropriate therapy strategy. ${ }^{3}$ Fractional flow reserve (FFR) is an innovative method for evaluating the physiological significance of a coronary stenosis and is defined as the ratio of maximal blood flow in a stenotic artery to normal maximal 
flow in the absence of a stenosis. International guidelines have recognized the value of FFR in guiding clinical therapy in patients with stable CAD. ${ }^{4,5}$ However, the validity of FFR is less certain in patients with non-ST-segment elevation myocardial infarction (NSTEMI), and it is an essential issue to assess whether FFR is effective and safe in these patients. ${ }^{6}$ Age and ethnicity-related changes in cardiovascular structure and function have an inevitable effect on FFR, and the role of FFR in clinical therapy of elderly Chinese patients with NSTEMI has not been explored. As the first one in China, the purpose of this study was to establish the efficacy and safety outcomes of FFR in guiding clinical therapy of NSTEMI compared with angiography alone in elderly Chinese patients.

\section{Patients and methods Participants}

This prospective randomized controlled study included 220 patients with NSTEMI older than 65 years of age and was performed in the Department of Cardiology from September 2013 to June 2016. NSTEMI was diagnosed based on acute ischemic symptoms and abnormal myocardial markers but without ST-segment elevation on the electrocardiogram. Exclusion criteria were as follows: 1) ongoing ischemic symptoms after medical therapy; 2) cardiogenic shock or hemodynamic instability; 3 ) intolerance to antiplatelet drugs; 4) ineligibility for percutaneous coronary intervention (PCI); 5) CAD <30\% severity; 6) highly tortuous or calcified coronary arteries; 7) noncoronary cardiosurgery; and 8) life expectancy $<1$ year. This study was approved by the ethics committee of Chinese People's Liberation Army General Hospital and conducted in line with the Declaration of Helsinki. All patients enrolled in this study provided their written informed consent.

\section{Processes}

In the clinical medical and invasive therapy, evidence-based guidelines were followed. ${ }^{7-9}$ Angiography was performed using standard catheterization room equipment and evaluated visually by an experienced clinician who determined the therapy strategy based on the coronary stenosis severity (stenosis $\leq$ or $>70 \%$ of reference vessel diameter $[50 \%$ for left main]). Patients were assigned in a ratio of $1: 1$ to the FFR-guided group and the angiography-guided group using random digits in a randomized block design. After coronary dilation caused by intravenous infusion of adenosine $(140 \mu \mathrm{g} / \mathrm{kg} / \mathrm{min})$, patients in the FFR-guided group had
FFR measured using a pressure-sensitive coronary guidewire (St Jude Medical, Inc., St Paul, MN, USA). A cutoff point of 0.80 was the standard selecting PCI $(\leq 0.80)$ or medical therapy alone $(>0.80)$.

\section{Outcomes}

The following outcomes were evaluated after 1 year of follow-up: 1) adverse events, including major adverse cardiovascular event defined as cardiovascular death, nonfatal myocardial infarction, or unplanned hospitalization for heart failure, major adverse cardiovascular and cerebrovascular event defined as cardiovascular death, nonfatal myocardial infarction, unplanned hospitalization for stroke, or transient ischemic attack, all-cause mortality, contrast nephropathy, and major bleeding, and 2) therapy strategies (PCI or medical therapy alone).

\section{Statistics}

Continuous data were presented as mean (standard deviation) or median (interquartile range), and categorical data were presented as number (percentage). Continuous variables between the two groups were compared using Student's $t$-test or Mann-Whitney $U$ test, and categorical variables between the two groups were compared using Chi-square test. All analyses were two tailed at the 5\% significance level using Statistical Package for the Social Sciences Version 17.0 software (SPSS Inc., Chicago, IL, USA).

\section{Results}

The mean age of all patients were $70 \pm 3.6$ years, and $69.6 \%$ were men. As shown in Table 1, baseline characteristics of patients had no differences between the two groups $(P>0.05$ for all). As shown in Table 2, no differences in adverse events including major adverse cardiovascular event, major adverse cardiovascular and cerebrovascular event, cardiovascular death, nonfatal myocardial infarction, heart failure, stroke, transient ischemic attack, all-cause mortality, contrast nephropathy, and major bleeding were observed between the two groups during the follow-up ( $P>0.05$ for all). Based on angiography alone, there were nine patients receiving medical therapy alone in the FFR-guided group and no difference with patients in the angiography-guided group $(P>0.05)$. Based on FFR, the other six patients $(5.5 \%)$ received medical therapy alone in the FFR-guided group. Patients receiving medical therapy alone in the FFR-guided group (15 patients) were significantly more than those in the angiography-guided group (six patients; $P<0.05$ ). 
Table I Baseline characteristics of patients in clinical therapy guided by FFR or angiography alone

\begin{tabular}{|c|c|c|c|}
\hline Characteristics & $\begin{array}{l}\text { FFR-guided } \\
\text { group } \\
(n=I \mid 0)\end{array}$ & $\begin{array}{l}\text { Angiography- } \\
\text { guided group } \\
(\mathrm{n}=110)\end{array}$ & $P$-value \\
\hline Age, years, mean $\pm S D$ & $70 \pm 3.7$ & $70 \pm 3.4$ & 0.267 \\
\hline Men, n (\%) & $75(68.2)$ & 78 (70.9) & 0.660 \\
\hline Smoking, n (\%) & & & 0.908 \\
\hline Current & $29(26.4)$ & $31(28.2)$ & \\
\hline Former & $4 \mathrm{I}(37.3)$ & $38(34.5)$ & \\
\hline Never & $40(36.4)$ & $4 \mathrm{I}(37.3)$ & \\
\hline Previous MI, n (\%) & $24(21.8)$ & $23(20.9)$ & 0.869 \\
\hline Heart failure, n (\%) & $2(1.8)$ & $\mathrm{I}(0.9)$ & 1.000 \\
\hline Hypertension, n (\%) & $81(73.6)$ & $83(75.5)$ & 0.757 \\
\hline Diabetes mellitus, n (\%) & $40(36.4)$ & $36(32.7)$ & $0.57 \mid$ \\
\hline Hyperlipidemia, n (\%) & $90(81.8)$ & $93(84.5)$ & 0.589 \\
\hline \multicolumn{4}{|l|}{ Peak troponin levels, n (\%) } \\
\hline$>\times 5$ upper limit of normal & $87(79.1)$ & $82(74.6)$ & 0.424 \\
\hline$>\times 10$ upper limit of normal & $69(62.7)$ & $64(58.2)$ & 0.491 \\
\hline \multicolumn{4}{|l|}{ Procedural characteristics, n (\%) } \\
\hline Radial artery access & $95(86.4)$ & $98(89.1)$ & 0.538 \\
\hline Aspirin & $110(100.0)$ & $110(100.0)$ & \\
\hline Clopidogrel & $89(80.9)$ & $86(78.2)$ & 0.616 \\
\hline Ticagrelor & $21(19.1)$ & $24(21.8)$ & 0.616 \\
\hline Statin & $103(93.6)$ & $105(95.5)$ & 0.553 \\
\hline Beta-blocker & $74(67.3)$ & $73(66.4)$ & 0.886 \\
\hline $\mathrm{CCB}$ & 45 (40.9) & $49(44.6)$ & 0.586 \\
\hline Nitrates & $98(89.1)$ & $96(87.3)$ & 0.676 \\
\hline LMWH & 101 (91.8) & $102(92.7)$ & 0.801 \\
\hline
\end{tabular}

Abbreviations: $\mathrm{CCB}$, calcium channel blocker; FFR, fractional flow reserve; LMWH, low molecular weight heparin; MI, myocardial infarction; SD, standard deviation.

Table 2 Outcomes of patients in clinical therapy guided by FFR or angiography alone

\begin{tabular}{|c|c|c|c|}
\hline Outcomes & $\begin{array}{l}\text { FFR-guided } \\
\text { group } \\
(n=|| 0)\end{array}$ & $\begin{array}{l}\text { Angiography-guided } \\
\text { group } \\
(\mathrm{n}=\mathrm{I} \mid 0)\end{array}$ & $P$-value \\
\hline \multicolumn{4}{|l|}{ Adverse events } \\
\hline MACE & $9(8.2)$ & II (I0.0) & 0.639 \\
\hline MACCE & $10(9.1)$ & $13(11.8)$ & 0.509 \\
\hline Cardiovascular death & $4(3.6)$ & $5(4.5)$ & 0.734 \\
\hline Nonfatal MI & $5(4.5)$ & $7(6.4)$ & 0.553 \\
\hline Heart failure & $4(3.6)$ & $5(4.5)$ & 0.734 \\
\hline Stroke & $0(0)$ & I (0.9) & 1.000 \\
\hline TIA & I (0.9) & I (0.9) & 1.000 \\
\hline All-cause mortality & $9(8.2)$ & II $(10.0)$ & 0.639 \\
\hline Contrast nephropathy & $0(0)$ & $2(1.8)$ & 0.477 \\
\hline Major bleeding & $2(1.8)$ & $3(2.7)$ & 1.000 \\
\hline Therapy strategies & & & 0.039 \\
\hline Medical therapy & $15(13.6)$ & $6(5.5)$ & \\
\hline $\mathrm{PCl}$ & $95(86.4)$ & $104(94.5)$ & \\
\hline
\end{tabular}

Notes: Data presented as $n(\%)$. MACE is defined as cardiovascular death, nonfatal $\mathrm{MI}$, or unplanned hospitalization for heart failure; MACCE is defined as cardiovascular death, nonfatal MI, unplanned hospitalization for stroke, or TIA.

Abbreviations: FFR, fractional flow reserve; MACE, major adverse cardiac event; MACCE, major adverse cardiac and cerebral event; MI, myocardial infarction; $\mathrm{PCl}$, percutaneous coronary intervention; TIA, transient ischemic attack.

\section{Discussion}

The current standard method applied for clinical therapy of NSTEMI is angiography with visual interpretation of anatomical severity of a coronary stenosis. FFR is an innovative method evaluating the physiological significance of a coronary artery stenosis and is able to determine the therapy strategies. FFR is gradually applied in patients with stable CAD due to the approval of international guidelines. However, in patients, especially elderly Chinese patients, with NSTEMI, FFRguided therapy is not the standard method, mainly because of lacking evidence. This study showed that FFR-guided therapy reduced the application of PCI and obtained similar outcomes compared with angiography alone, demonstrating that FFR was effective and safe in guiding clinical therapy of NSTEMI in elderly Chinese patients.

FFR had important implications in advancing clinical therapy of stable CAD. ${ }^{10}$ Studies such as DEFER and FAME have confirmed the benefits of FFR in stable CAD to more precisely guide the clinical therapy. ${ }^{11,12}$ The validity of FFR is less clear in patients with acute coronary syndrome (ACS) due to the likelihood that coronary response to vasodilators may be decreased due to coronary obstruction. Coronary lesion of patients with ST-segment elevation myocardial infarction may limit the dilatation of coronary and the validity of FFR.${ }^{13}$ However, FFR may be valuable in patients with NSTEMI because its lesion is typically nonocclusive thrombotic plaque rupture and subendocardial infarction with transient coronary dysfunction and preserved blood flow. ${ }^{14}$ Coronary reserve has been found to be similar in patients with stable angina and NSTEMI, which is consistent with preserved dilation ability in patients with stable ACS. ${ }^{14}$ A post hoc analysis of patients with stable ACS in the FAME study has suggested the validity of FFR..$^{15}$ The FAMOUS-NSTEMI study has reported on the efficacy and safety of FFR-guided therapy in patients with NSTEMI. ${ }^{16}$

Uncertainty for FFR application was specifically addressed in elderly Chinese patients and similarly caused by lacking evidence. In a post hoc analysis of patients in the FAME study, Lim et $\mathrm{al}^{17}$ have highlighted that FFR-guided therapy was similarly beneficial irrespective of age. Results of this study also illustrated that FFR was feasible because it not only determined the decreased application of PCI but was also not associated with worse outcomes in elderly Chinese patients with NSTEMI.

This study had several limitations. The sample size is relatively small, and the follow-up duration is relatively short in this study, so it is necessary to conduct large-scale 
studies with long follow-up periods to confirm the results obtained from this study.

\section{Conclusion}

This study confirmed that, compared with angiographyguided standard therapy, FFR reduced the application of PCI and obtained similar outcomes, demonstrating that FFR was effective and safe in guiding clinical therapy of NSTEMI in elderly Chinese patients.

\section{Disclosure}

The authors report no conflicts of interest in this work.

\section{References}

1. Go AS, Mozaffarian D, Roger VL, et al. Heart disease and stroke statistics - 2014 update: a report from the American Heart Association. Circulation. 2014;129:e28-e292.

2. World Health Organisation [webpage on the Internet]. Cardiovascular disease. Available from: http://www.who.int/cardiovascular_diseases/en/. Accessed March 15, 2015.

3. Berry C, Corcoran D, Hennigan B, Watkins S, Layland J, Oldroyd KG. Fractional flow, reserve-guided management in stable coronary disease and acute myocardial infarction: recent developments. Eur Heart J. 2015;36(45):3155-3164.

4. Montalescot G, Sechtem U, Achenbach S, et al. ESC guidelines on the management of stable coronary artery disease: the Task Force on the management of stable coronary artery disease of the European Society of Cardiology. Eur Heart J. 2013;34:2949-3003.

5. Windecker S, Kolh P, Alfonso F, et al. ESC/EACTS guidelines on myocardial revascularization: The Task Force on Myocardial Revascularization of the European Society of Cardiology (ESC) and the European Association for Cardio-Thoracic Surgery (EACTS) developed with the special contribution of the European Association of Percutaneous Cardiovascular Interventions (EAPCI). Eur Heart J. 2014;35:2541-2619.

6. Cuculi F, De Maria GL, Meier P, et al. Impact of microvascular obstruction on the assessment of coronary flow reserve, index of microcirculatory resistance, and fractional flow reserve after ST-segment elevation myocardial infarction. J Am Coll Cardiol. 2014;64(18):1894-1904.

7. Hamm CW, Bassand JP, Agewall S, et al. ESC Guidelines for the management of acute coronary syndromes in patients presenting without persistent ST-segment elevation: The Task Force for the management of acute coronary syndromes (ACS) in patients presenting without persistent ST-segment elevation of the European Society of Cardiology (ESC). Eur Heart J. 2011;32:2999-3054.
8. Wright RS, Anderson JL, Adams CD, et al. ACCF/AHA focused update of the Guidelines for the Management of Patients with Unstable Angina/ Non-ST-Elevation Myocardial Infarction (updating the 2007 guideline): a report of the American College of Cardiology Foundation/American Heart Association Task Force on Practice Guidelines developed in collaboration with the American College of Emergency Physicians, Society for Cardiovascular Angiography and Interventions, and Society of Thoracic Surgeons. J Am Coll Cardiol. 2011;57:e215-e367.

9. Wijns W, Kolh P, Danchin N, et al. Guidelines on myocardial revascularization. Eur Heart J. 2010;31:2501-2555.

10. Tonino PA, de Bruyne B, Pijls NH, et al; FAME Study Investigators. Fractional flow reserve versus angiography for guiding percutaneous coronary intervention. N Engl J Med. 2009;360(3):213-224.

11. Pijls NH, van Schaardenburgh P, Manoharan G, et al. Percutaneous coronary intervention of functionally nonsignificant stenosis: 5-year follow-up of the DEFER Study. J Am Coll Cardiol. 2007;49(21): 2105-2111.

12. Tonino PA, Fearon WF, De Bruyne B, et al. Angiographic versus functional severity of coronary artery stenoses in the FAME study fractional flow reserve versus angiography in multivessel evaluation. J Am Coll Cardiol. 2010;55(25):2816-2821.

13. Uren NG, Crake T, Lefroy DC, de Silva R, Davies GJ, Maseri A. Reduced coronary vasodilator function in infarcted and normal myocardium after myocardial infarction. N Engl J Med. 1994;331(4):222-227.

14. Layland J, Carrick D, McEntegart M, et al. Vasodilatory capacity of the coronary microcirculation is preserved in selected patients with nonST-segment-elevation myocardial infarction. Circ Cardiovasc Interv. 2013;6(3):231-236.

15. Sels JW, Tonino PA, Siebert U, et al. Fractional flow reserve in unstable angina and non-ST-segment elevation myocardial infarction experience from the FAME (fractional flow reserve versus angiography for multivessel evaluation) study. JACC Cardiovasc Interv. 2011;4(11): 1183-1189.

16. Layland J, Oldroyd KG, Curzen N, et al; FAMOUS-NSTEMI investigators. Fractional flow reserve vs. angiography in guiding management to optimize outcomes in non-ST-segment elevation myocardial infarction: the British Heart Foundation FAMOUS-NSTEMI randomized trial. Eur Heart J. 2015;36(2):100-111.

17. Lim HS, Tonino PA, De Bruyne B, et al. The impact of age on fractional flow reserve-guided percutaneous coronary intervention: a FAME (fractional flow reserve versus angiography for multivessel evaluation) trial substudy. Int J Cardiol. 2014;177(1):66-70.
Clinical Interventions in Aging

\section{Publish your work in this journal}

Clinical Interventions in Aging is an international, peer-reviewed journal focusing on evidence-based reports on the value or lack thereof of treatments intended to prevent or delay the onset of maladaptive correlates of aging in human beings. This journal is indexed on PubMed Central, MedLine,

\section{Dovepress}

CAS, Scopus and the Elsevier Bibliographic databases. The manuscript management system is completely online and includes a very quick and fair peer-review system, which is all easy to use. Visit http://www.dovepress. com/testimonials.php to read real quotes from published authors. 